\title{
HIGH DEFINITION ENDOSCOPY AND “NARROW BAND IMAGING" IN THE DIAGNOSIS OF GASTROESOPHAGEAL REFLUX DISEASE
}

\author{
Diagnóstico da doença do refluxo gastroesofágico com endoscopia de alta definição e "narrow band imaging" \\ Frederico Salvador ASSIRATI, Cláudio Lyoiti HASHIMOTO, Ricardo Anuar DIB, \\ Luiz Henrique Souza FONTES, Tomás NAVARRO-RODRIGUEZ
}

\begin{abstract}
From the Departamento de Gastroenterologia, Hospital das Clínicas, Faculdade de Medicina, Universidade de São Paulo (Department of Gastroenterology, Hospital de Clínicas, School of Medicine, University of São Paulo), São Paulo, SP, Brazil
\end{abstract}

HEADINGS - Gastroesophageal reflux disease. Barrett's esophagus. Narrow band imaging. High definition endoscopy.
ABSTRACT - Introduction: The gastroesophageal reflux disease is a common condition in the western world but less than half of patients present endoscopic abnormalities, making a standard procedure unsuitable for diagnosis. High definition endoscopy coupled with narrow band imaging has shown potential for differentiation of lesions and possible biopsy, allowing early diagnosis and treatment. Methods: This review describes the principles of biotic and their influence in obtaining images with better definition of the vessels in the mucosa, through the narrow band imaging. Selected papers using it in patients with reflux disease and Barrett's esophagus are analyzed in several ways, highlighting the findings and limitations. Conclusion: The meaning of the narrow band imaging in the endoscopic diagnosis of reflux disease will be defined by large scale studies, with different categories of patients, including assessment of symptoms and response to treatment.

\author{
Correspondence: \\ Frederico Salvador Assirati \\ Email: fjassirati@yahoo.com.br \\ Fonte de financiamento: não há \\ Conflito de interesses: não há \\ Recebido para publicação: 11/06/2013 \\ Aceito para publicação: 18/10/2013
}

DESCRTTORES - Doença do refluxo gastroesofágico. Esôfago de Barrett. Narrow band imaging. Endoscopia de alta definição.
RESUMO - Introdução: A doença do refluxo gastroesofágico é condição altamente prevalente no mundo ocidental, porém, em menos da metade dos pacientes há alguma alteração endoscópica, indicando que a endoscopia convencional não é o procedimento ideal para o diagnóstico da doença do refluxo gastroesofágico. A endoscopia com aparelhos de alta definição associado ao dispositivo "narrow band imaging" tem demonstrado aplicação na diferenciação de lesões benignas das malignas e a possibilidade de direcionar as biópsias, permitindo diagnóstico e tratamento especialmente nos casos de câncer precoce. Método: Esta revisão descreve os princípios ópticos e sua influência na obtenção de imagens de vasos na mucosa, através da "narrow band imaging". Foram utilizados os descritores para pesquisa no PubMed e as publicações analisadas em diversos aspectos com destaque para o "narrow band imaging", seus fundamentos, aplicações e limitações. Conclusão: O significado do "narrow band imaging" no diagnóstico endoscópico da doença do refluxo gastroesofágico será definido por estudos em larga escala, com categorias diferentes de pacientes, incluindo avaliação de sintomas e resposta ao tratamento.

\section{INTRODUCTION}

T he upper gastrointestinal endoscopy has had major technological advancements in the past decades, causing great impact on diagnostic accuracy. It started in the $60 \mathrm{~s}$, with the optical fiber endoscope, important tool to deal with several gastroenterological conditions. Twenty years after that, conventional videoendoscopy appeared with improvements in both definition and image resolution, which increased from 100,000 to 300,000 pixels.

However, identifying esophageal conditions by means of conventional videoendoscopy is limited to the presence of lesions in the mucosa, such as plaques, erosions, ulcers or nodules. As a result, the gastroesophageal reflux disease (GERD), which is a highly common condition in the western world, presents abnormalities in the endoscopic exam in less than half of the patients with typical symptoms. Therefore, the standard procedure is not very sensitive to diagnose it ${ }^{19}$. 
In view of the need for more diagnostic accuracy, high definition endoscopy coupled with narrow band imaging (NBI) was developed. It enables image resolution of one million pixels, which increases the diagnostic accuracy in biopsy of several esophageal conditions.

\section{Narrow band imaging}

Its development was made available by Olympus Medical Systems in Japan. It was first reported by Sano et al. ${ }^{22}$ in 1999 and introduced in commercial scale in 2005.

The NBI is an important advancement in endoscopy technology, based on the physics principle that the penetration depth of light waves in the tissues is directly proportional to its size. Therefore, the longest the wave, the deeper the penetration in the tissues ${ }^{7}$.

The use of spectral filters (red, green and blue strips) of the NBI highlights the characteristics of the mucosa and vascular patterns of the esophagus, stomach and colon with better definition when compared to the standard endoscopic exam. Two systems are currently available to use endoscopy with NBI. The sequential magnifying system with high resolution endoscope (GIF Z160), which enables optical magnification of up to 80 times and the "charged coupled device" system of the high definition device (high-definition television) - GIF H 180, which has digital zoom with magnifying potential from 1.2 to 1.5 times. This image magnification associated to the NBI improves diagnostic accuracy resulting from the detailed assessment of the pattern of capillary intrapapillary mucosa vessels.

However, the NBI has the disadvantage of a dark image, which makes it impossible to identify abnormalities in the color and morphology of lesions, when located far from the endoscope.

\section{Light and biotic principles}

Unlike conventional image processing, the NBI highlights the image obtained through light filters. The light visible to the human eye is made up by a limited range of wavelengths of electromagnetic radiation which are located between the infrared and infraviolet radiation.

When the light falls upon the tissue, part is reflected on the surface and part is dispersed within the very tissue. The multiple scattering occurs between light and the small particles such as nucleus, cell organelles and nucleolus on the tissues, resulting in diffuse light propagation along the tissue, dependent on its wavelength. Because it has long wavelength, the red light is widely and deeply scattered. The blue light, on the other hand, scatters less deeply, for it presents short wavelength.

Part of the light scattered is absorbed by the blood, and the color of the mucosa is mainly determined by hemoglobin since most of the components of the gastrointestinal mucosa - cells and connective tissue - do not present any color. The interaction between light and tissue is characterized by hemoglobin, which absorbs intensely both the green and the blue light.

NBI is based on this idea and was developed with the aim of highlighting the blood vessels, not reproducing its natural colors.

The best imagine is the one with the best resolution and contrast. Resolution is defined as the ability to reveal details of the image (determined by the number of pixels), signal processing and characteristics of the lens. Contrast is the ratio of density or brightness between a pattern and its background, in other words, the clarity with which the object is highlighted ${ }^{7}$.

The NBI can selectively improve the contrast of the blood vessels. The best resolution is obtained through the high definition television, and the use of NBI improves contrast. As a result, combining high definition TV with NBI may offer high quality images of the blood vessels ${ }^{7}$. According to the NBI principle, the selection of 415 nanometer waves highlight capillary vessels of the subepithelial layer of the mucosa and the 540 nanometer waves enable better visibility of vessels of higher caliber of the submucosal layer. On the other hand, deeper vessels are reproduced in 600 nanometer images. The use of 600-nanometer waves has little diagnostic application, since initial neoplasies develop in the shallow surfaces of the mucosa, altering the structure of its blood vessels. That is the main reason for NBI to generally use two bands of wavelength (415 and 540 nanometers).

\section{Narrow band imaging system}

There is an optical filter and a xenon lamp in front of the NBI system and, when activated, the white light that passes through this filter and lamp divides the light, allowing passage of only two wavelength bands (415 and 540 nanometers), which will fall upon the mucosa and when deactivated, the optical filter is removed from the light. This reflected light is captured by the "charged coupled device" at the distal portion of the endoscope, which converts it into digital value and the image is then reconstructed in a specific processor.

This "charge coupled device" consists of a sensor made up by an integrated circuit which contains the matrix of coupled devices to capture images. The "charged coupled devices" are also used in digital photography, satellite images and astronomy (especially in photometric, optics and ultraviolet spectroscopy). The resolution or image detailing depends on the number of photoelectric cells of the "charge coupled device", which in practical terms are expressed as pixels. The higher the number of pixels, the better the image resolution. For instance, today the digital cameras incorporate "charged coupled 
devices" with up to 160 million pixels.

The "charged coupled device" captures and transfers the entire white light spectrum for the processor to reconstruct the natural color of the video monitor. In order to get colored images, three images are released to the three channels of the monitor (red, green and blue), and the signs are converted from analogical to digital. The reconstruction of the incomplete NBI image does not have adequate contrast for superficial capillary networks. However, this may be corrected by processing through a computer connected to a second monitor. Capillary contrast in a hazel color occurs through digital processing.

In short, when NBI is activated, two images are obtained: an incomplete, non processed image, shown on the video monitor of the endoscope, and another one processed on the computer monitor (Figure 1).

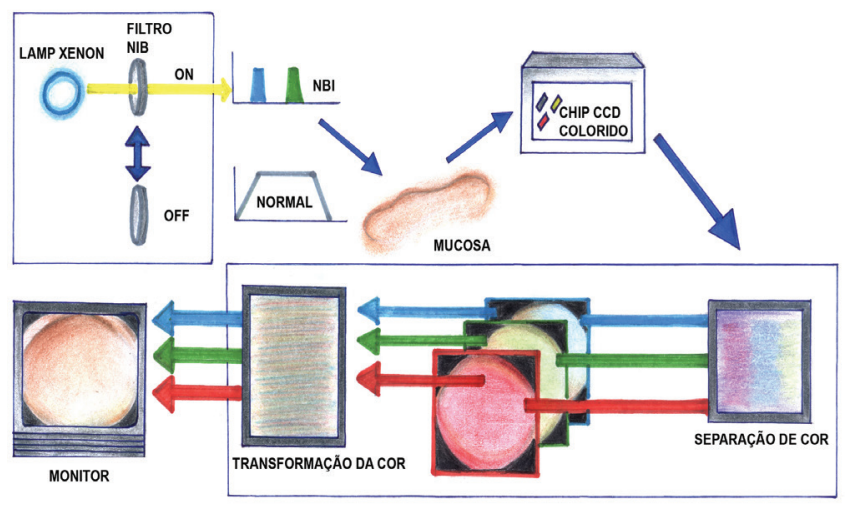

FIGURE 1 - NBI System

\section{Blood vessels and bleeding}

The capillaries of the epithelial layer of the mucosa during NBI application have a brownish color and, without magnification, they look like small brownish spots. The blood vessels of higher caliber found on the deeper layers of the mucosa have a bluish color. However, when there is active bleeding, the use of NBI makes the blood look black, because the wavelengths of 415 and 540 nanometers are totally absorbed by the blood, with no reflection.

Neoplastic lesions usually present high level of cell proliferation and high density of blood vessels. When there is carcinoma of the squamous cells of the esophagus, the intrapapillary capillaries increase (in number and caliber) with sharp tortuosity highlighted by the NBI as a well limited area of brownish color ${ }^{14}$.

In the area of esophageal gastric transition, the stratified squamous epithelium of the normal esophageal mucosa has few blood vessels and reflects the white light of standard endoscopy intensely. However, the visibility with NBI has a white-bluish color. On the other hand, the surface of the gastric mucosa has a rich network of capillaries and blood vessels, and a brownish color is observed at the NBI. Therefore, the extension of mucosa of Barrett's esophagus the can be easily detected through the contrast with the normal esophagus mucosa, since the distal esophagus has palisade vascularization. This characteristic contrasts with the cardiac vessels and capillaries, helping differentiation with Barrett's esophagus.

\section{Use of high definition endoscopy and NBI}

The high definition endoscopes with NBI resources (Olympus GIF-H180 ${ }^{\circledR}$ ) are identical to the standard ones regarding ergonomics and it differ in a few functions, such as NBI activation, magnification, pause and image capture. The endoscopes are not compatible with processors from previous generations, and for full use need a specific model (Olympus Exera II CV $180 \circledR$ ).

The time of exam for upper gastrointestinal endoscopy with NBI and high definition endoscopy is longer and requires more collaboration from the patient when compared to the standard procedure. When sedation is insufficient, the patient may move during the exam, which makes it impossible to have a detailed observation of the surface of the mucosa and blood vessels.

The esophagus assessment with NBI can be maximized with the use of a small transparent "CAP" cylinder at the distal end of the endoscope. This CAP is used to keep the tip of the endoscope away from the organ, offering support and keeping a constant distance of about two to three millimeters from the mucosa. As a result, better images with better focus can be obtained, and also restricted line of sight, which is appropriate for detailed assessment of the mucosa.

The presence of mucous and saliva may interfere in obtaining clear images to study the esophagus with NBI. Therefore, preparation with $\mathrm{N}$-acetylcysteine (10 to $20 \mathrm{ml}$ ) with a spray catheter and water help clean the surface of the mucosa. The use of butylscopolamine as antispasmodic and peristaltic inhibitor of the gastrointestinal tract may be used to decrease the esophagus gastroduodenal motility, which makes the observation of its mucosa easier ${ }^{2}$.

\section{Examining the esophagus}

First of all, the standard procedure with white light is performed to assess irregularities of the mucosa, such as color alteration, nodules, erosions, ulcers or plaques. The abnormalities found must be reassessed using the NBI for a detailed study. Biopsies will be performed at the end of the procedure, once the presence of blood interferes in the NBI exam.

The endoscopist should be attentive to two aspects: the surface of the mucosa and the vascular pattern. Normal pattern of mucosa will be better assessed given the possibility of finding abnormal vascular pattern.

NBI enables clear observation of the microvascular structure, including the pattern of the intrapapillary 
capillary loops. The intrapapillary capillary loops are delicate vessels, of small diameter, located vertically with approximately $10 \mu \mathrm{m}$ in size. The blood vessel looks green in the NBI, while the intrapapillary capillary loops have a brownish color. The pattern for intrapapillary capillary loops has been classified as type I (normal esophagus), II (regenerative tissue or inflammation), III (borderline lesion) and IV-V (intraepithelial neoplasia with high grade of invasive cancer) (Figure 2).

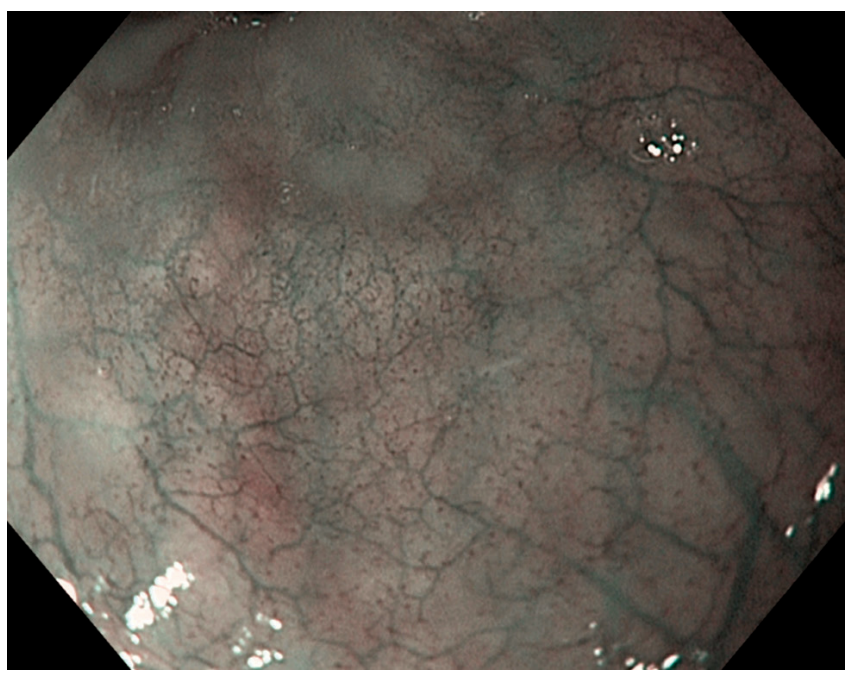

FIGURE 2 - Normal esophagus (type I)

\section{Gastroesophageal reflux disease}

GERD is a highly prevalent condition in the western world, affecting around $20-50 \%$ of adults, and is associated to the great economic impact ${ }^{16}$.

Based on endoscopic findings, patients with GERD are divided into the following categories: non-erosive gastroesophageal reflux disease (NERD), erosive esophagitis and Barrett's esophagus (BE). Around one third of the patients have endoscopic evidence of erosive esophagitis characterized by damage in the integrity of the mucosa and one fifth of the patients present complex gastroesophageal reflux disease (ulcerous esophagitis, esophageal stenosis and $\mathrm{BE})^{8}$. Considering that more than $50 \%$ of the patients with GERD do not present erosive esophagitis alterations, standard endoscopy is not a very sensitive exam to diagnose GERD ${ }^{16,19}$.

The tem GERD is used for patients with normal endoscopy, who present symptoms of gastroesophageal reflux and/or altered pHmetrics, and who may present small superficial abnormalities non visible by means of standard endoscopy.

Over the past years, technological advances have taken place with the aim of overcoming such difficulties, namely the high definition endoscopy with NBI and/or magnification, which aim at detecting minimal abnormalities in the esophageal mucosa of patients with GERD.
In a study applying endoscopy with image magnification, Kiesslich et al. ${ }^{12}$ have shown that patients with NERD presented endoscopic signs of esophagitis with minimal abnormalities proven by histological alterations significantly more frequently in comparison with the control group (sensitivity $62 \%$ and specificity $74 \%$ ).

Sharma et al. ${ }^{23}$ assessed the squamous columnar transition in four patients (three with erosive esophagitis and one with NERD) and two control subjects, and noticed better visualization with NBI when compared to standard endoscopy for the following parameters: 1 ) increase in number, dilatation and tortuosity of the intrapapillary capillary loops; 2 ) presence of microerosions; 3 ) increase in the vascular network at the squamocolumnar junction; 4) loss of the palisade pattern of the blood vessels above the " $Z$ " line; 5) viliform columnar mucosa with triangular indentations in the squamocolumnar mucosa, and 6) islands of distal squamous epithelium in line " $Z$ ".

Subsequently, these characteristics were also observed in 50 patients (30 with erosive esophagitis and 20 with non erosive gastroesophageal reflux disease) when compared to 30 control subjects. The patients with erosive esophagitis presented dilated intrapapillary capillary loops (66\%vs.13\%), tortuous intrapapillary capillary loops (80\%vs.37\%), microerosions (52\%vs.0\%) and increase in vascularity of the gastroesophageal junction (40\%vs.7\%) more frequently, compared with control subjects. Patients with non erosive gastroesophageal reflux disease, when compared to control subjects, also presented increase in the intrapapillary capillary loops (55\%vs.13.3\%) and dilatation of intrapapillary capillary loops (65\%vs.16,7\%), indicating similarities in the abnormalities in both groups. The sensitivity and specificity of the abnormalities of the intrapapillary capillary loops, such as increase in number, dilatation, tortuosity and microerosions to identify patients with GERD was $94 \%$ and $63 \%$, respectively. The interobserver agreement for these findings varied from moderate to almost perfect (Kappa coefficient).

The advantages of the NBI method when compared to standard chromoendoscopy are: the possibility for a detailed inspection of the mucosa and vascular pattern; differently, with the standard chromoendoscopy it is more difficult to identify the intrapapillary capillary loops. The limitations of the NBI method are the small areas of the esophagus studied (they increase procedure time) and the learning curve (should be higher, for it will affect the assessment results).

Lee et al. ${ }^{15}$ investigated the inter and intraobserver agreement to grade images of the gastroesophageal junction with NBI using the Los Angeles classification for erosive esophagitis. Images of the gastroesophageal junction of 230 consecutive patients were presented to seven endoscopists: in the 
first stage, the ones obtained through the standard procedure and then the ones obtained through NBI endoscopy. The combined assessment using NBI improved the inter and intraobserver agreement considerably. It is important to point out that the assessment of esophagitis has changed after the NBI. It changed from normal to erosive in a considerable number of patients, most likely because of a better visualization of the breakdown in the mucosal integrity. These results may enable the development of a new classification for esophagitis.

In a prospective study, Fock et al. ${ }^{6}$ have assessed the NBI capability to distinguish patients with erosive esophagitis and NERD from control subjects. The NBI has improved the definition of microerosions, vascularity and islands of mucosa ("pit patterns") when compared to the standard procedure. Patients with erosive esophagitis and NERD had microerosions and vascularity more frequently when compared to the control subjects, and differentiate between each other only because of an increase of the vascular surface and absence of "pit patterns" (sensitivity $86.1 \%$ and specificity $83.3 \%$ ). With these findings, although NBI endoscopy cannot be considered the standard procedure to diagnose GERD yet, it may be useful to classify the erosive and non erosive gastroesophageal reflux disease.

Tseng et al. ${ }^{27}$ have assessed NBI and endoscopy with and without magnification to anticipate the therapeutic response in patients with gastroesophageal reflux. Eighty-two were assessed, and erosive disease was diagnosed in 14 of them (23.3\%) through standard procedure, $22(26.8 \%)$ through endoscopy associated to NBI and 30 (50\%) when NBI was associated to magnification. Sixty-five patients (79.3\%) had a positive therapeutic response (Table 1 ).

TABLE 1 - Percentage of patients with diagnosis of non erosive gastroesophageal reflux (NERD) through standard procedure when compared to NBI and NBI with magnification ${ }^{27}$

\begin{tabular}{|l|c|c|c|}
\hline & $\begin{array}{c}\text { Standard } \\
\text { endoscopy }\end{array}$ & NBI & $\begin{array}{c}\text { NBI with } \\
\text { magnification }\end{array}$ \\
\hline Sensitivity (\%) & 33.8 & 52.3 & 72.8 \\
\hline Specificity (\%) & 100.0 & 88.2 & 64.7 \\
\hline Positive predictive value (\%) & 100.0 & 94.4 & 88.4 \\
\hline Negative predictive value (\%) & 28.3 & 32.6 & 36.6 \\
\hline Accuracy (\%) & 47.6 & 59.8 & 69.5 \\
\hline
\end{tabular}

The study has consistently revealed that a considerable proportion of patients with NERD (36.6\%) changed the diagnosis to erosive esophagitis (non-erosive GERD to erosive esophagitis) after the use of NBI with or without magnification. Using the therapeutic response as a standard reference, a graded increase in sensitivity from 33.8 to 52.3 and to 72.8 was observed, using the following sequence: standard endoscopy, NBI and NBI with magnification. The debatable aspects of the study were: a) biopsy of the mucosa was not performed; b) short period of treatment (two weeks) with a proton bomb inhibitor (which may be insufficient for some patients) and c) the esophageal pHmetrics was not performed. The study suggests that the endoscopic assessment with NBI enables the identification of patients with non erosive gastroesophageal reflux disease who would benefit from the treatment with proton pump inhibitors.

\section{Barrett's esophagus (BE)}

$\mathrm{BE}^{26}$ is characterized by the presence of columnar epithelium replacing the squamous epithelium, which normally covers the distal esophagus. This condition occurs when the GERD damages the esophagus mucosa and the lesion heals through a process of incomplete intestinal metaplasia, which predisposes the development of adenocarcinoma. The BE is usually diagnosed in the standard procedure, and can be confirmed by biopsy of the esophagus in areas of salmon color above the gastroesophageal junction.

The confirmation of BE calls for clinical followup according to protocols to detect dysplasia and/or cancer $^{28}$. However, the standard procedure may fail to identify abnormalities such as metaplasia, dysplasia and early adenocarcinoma in patients with BE due to the sparse distribution and subtle macroscopic abnormalities of these lesions ${ }^{8}$.

In a crossover randomized trial, Wolfsen e $\mathrm{cols}^{30}$ have shown a better result of the NBI in comparison to the standard procedure to detect dysplasia (57-43\%) associated to a smaller number of biopsies in the NBI group (average of 4.7 biopsies) when compared to standard procedure with four quadrant biopsies in the (average of 8.5 biopsies).

Currently, the recommended strategy to follow up on BE is to identify and perform biopsy in areas of mucosal abnormalities, such as granularity, plaques, polyps, ulcerations, erosions and subtle mucosal color changes. In the absence of such lesions, fourquadrant biopsies should be collected alleatorily at every two centimeters of the esophagus (Seattle protocol). However, this method is subject to sample mistakes, since biopsy is performed in only $3.5 \%$ of the mucosa at every two centimeters. Therefore, 96.5 of the mucosal tissue suspected of BE may not be analyzed in a sample. Moreover, it is noteworthy that only $41-56 \%$ of the endoscopic services follow the protocol ${ }^{8}$ closely. For this reason, the identification of areas suspected of dysplasia for biopsy would be a great clinical benefit when following up on patients with $\mathrm{BE}$.

Over the past years, a number of studies have assessed the use of NBI to identify pre-cancerous lesions in patients with $B E$, with promising findings (Figure 3). 


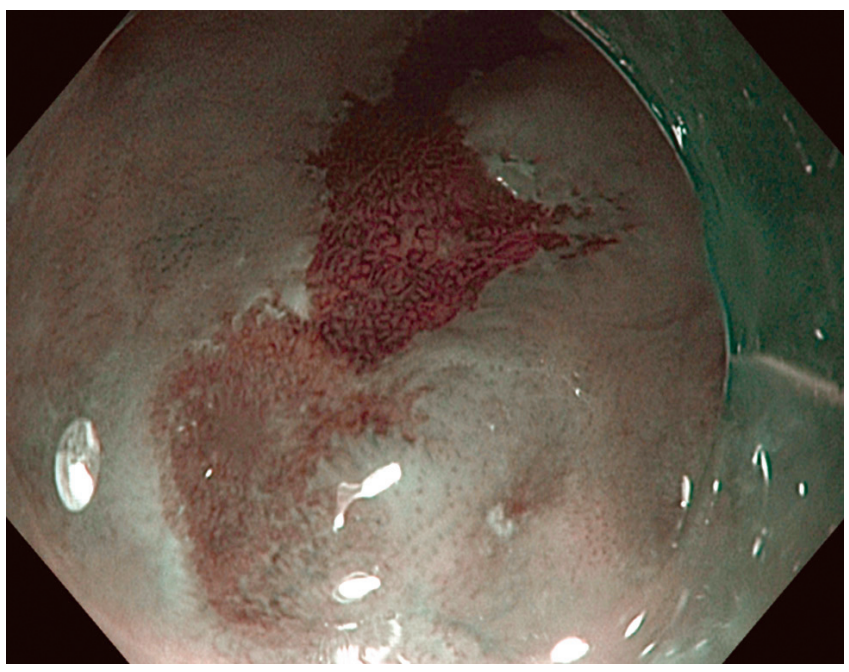

FIGURE 3 - Barrett's esophagus with high grade dysplasia

In a blind and prospective study, Wolfsen et al. ${ }^{29}$ have assessed 51 BE patients with NBI. The abnormalities observed at the NBI were classified according to the mucosal abnormalities (crests/ villosity - circular, irregular/distorted) and vascular patterns (normal, abnormal) and correlated with histology. The sensitivity, specificity and positive predictive value of the pattern of crests/villosity for the diagnosis of intestinal metaplasia without high grade dysplasia were 93.5\%, 86.7, and 94.7, respectively. The sensitivity, specificity and positive predictive value of the irregular/distorted pattern for high grade dysplasia were 100\%, 98.7, and 95.3, respectively. However, the NBI was unable to distinguish areas of intestinal metaplasia and low grade dysplasia.

In a study with similar methodology, Kara et al.. ${ }^{19}$ assessed 63 patients with BE according to the irregular mucosal and vascular pattern and presence of abnormal vessels detected at the NBI for the diagnosis of high grade dysplasia, obtaining sensitivity, specificity and negative predictive value of $94 \%, 76 \%$ and $98 \%$, respectively, results very similar to the ones obtained by Sharma et al. ${ }^{24}$.

Would electronic chromoendoscopy with NBI be better than standard chromoendoscopy? The answer to this question is still not clear. However, another study by Kara et al.. ${ }^{11}$ analyzing 28 patients with $\mathrm{BE}$ and comparing the effectiveness of indigo carmine chromoendoscopy and NBI with high definition endoscopy to detect early adenocarcinoma/ high grade dysplasia, reported sensitivity of indigo carmine chromoendoscopy and NBI to detect early adenocarcinoma/high grade dysplasia of $93 \%$ and $86 \%$ respectively, without significant statistic difference. Although NBI and chromoendoscopy detected a greater number of lesions, these techniques were not better than high definition endoscopy to identify patients with early adenocarcinoma/ high grade dysplasia.
It must be pointed out that these studies were performed with high risk populations, for their large number of patients with high grade dysplasia/ carcinomas. Moreover, all the studies used static images, which were obtained by experienced endoscopists, and areas with images of poor quality were discarded. The results of such studies possibly have biases bearing in mind there were greater chances of finding neoplasies in the population selected. Therefore, it may be difficult to reproduce it in the daily practice with BE patients, with less experienced endoscopists and limited amount of time to perform exams.

Despite the large number of papers published, only a few have compared the agreement of NBI and standard procedure among interobservers. When assessing mucosal abnormalities in patients with $\mathrm{BE}$, Curvers et al.. ${ }^{3}$ have analyzed the interobserver agreement (five experienced endoscopists and seven non specialist endoscopists) and observed moderate agreement among interobservers for mucosal and vascular patterns, using endoscopy with magnification, with no gain after adding NBI. Static images were used, representing a selection of better quality made by an expert endoscopist, in a high risk population.

\section{CONCLUSIONS}

Thestudy shows that the NBIimproves the sensitivity of endoscopy to diagnose GERD. Preliminary reports have shown that the intra-ephithelial papillary capillary loops (IPCLs) abnormalities are related to histological abnormalities present in the gastroesophageal reflux and these endoscopic abnormalities return to normal after treatment with proton pump inhibitors ${ }^{20}$.

The use of the NBI technology to diagnose GERD seems very promising, considering the low sensitivity of the standard procedure to diagnose such condition. Detecting discrete abnormalities caused by the gastroesophageal reflux may reduce the need for additional exams, such as 24-hour pHmetrics in patients with normal standard endoscopy.

New clinical trials in large scale assessing different categories of patients incorporating symptomatology, acid exposure where abnormalities are located and response to treatment may determine the meaning of NBI in the endoscopic diagnosis of GERD.

Preliminary studies of NBI in patients with BE have shown promising results with high sensitivity and specificity to differentiate between gastric mucosa and specialized intestinal metaplasia and BE without dysplasia and high grade dysplasia/carcinoma. In the first random and crossed study, NBI did not improve the detection of high grade dysplasia/carcinoma when compared to high definition endoscopy.

The promising results need validation by means of multicenter random studies to differentiate the 
histological characteristics and detection of high grade dysplasia/carcinoma. It would be relevant to carry out these studies in populations of normal/ intermediate risk of developing neoplasia. To this end, a uniform system of classification is necessary to assess the mucosal patterns and vascular network of BE with NBI, and this classification has to be validated, including agreement of inter and intraobservers ${ }^{4,17,18,21}$. A number of researchers are actively studying NBI and we may anticipate that future research will clarify its importance among other endoscopic procedures to identify and differentiate the various pathological conditions of the esophagus $25,930,13$.

\section{REFERENCES}

1. Abrams JA, Kapel RC, Lindenberg GM. Adherence to biopsy guidelines for Barrett's esophagus surveillance in the community setting in the United States. Clin Gastroenterol. Hepatol. 2009; 7: 736-42.

2. ASGE Technology Committee - Narrow band imaging and multiband imaging. Gastrointest Endosc 2008; 67: 581-9.

3. Curvers WL, Baak L, Kiesslich R. Chromoendoscopy and narrowband imaging compared with high resolution magnification endoscopy in Barrett's esophagus. Gastroenterol 2008;134: 670-9.

4. Curvers WL, van den Brock FJC, Reitsma JB, Dekker E, Bergman JJGHM. Systematic review of narrow band imaging for the detection and differentiation of abnormalities in the esophagus and stomach. Gastrointest Endosc 2009;69: 307-17.

5. Dent J, Armstrong D, Delaney B,Moayyedi P, Talley NJ, Vakil N. Symptom evaluation in reflux disease: workshop background, processes, terminology, recommendations, and discussions outputs. Gut 2004; 53(Suppl 4): 1-24.

6. Fock KM, Teo EK, Ang TL, Tan JYL, Law NM. The utility of narrow band imaging in improving the endoscopic diagnosis of gastroesophageal reflux disease. Clin Gastroent Hepatol 2009; 7: 54-9.

7. Gono K, Obi T, Yamaguchi M. Appearance of enhanced tissue features in narrow band endoscopic imaging. J Biomed Opt 2004; 9: 568-77.

8. Hamamoto $Y$, Endo $T$, Nosho $K$, Arimura $Y$, Sato $M$, Imai $K$. Usefulness of narrow band imaging endoscopy for diagnosis of Barrett's esophagus. J Gastroenterol 2004;39: 14-20.

9. Hatlebakk JG. Endoscopy in gastro-oesophageal reflux disease. Best Practice \& Res Clin Gastroenterol 2010;24: 775-86.

10. Kara MA, Ennahachi M, Fockens P. Detection and classification of the mucosal and vascular patterns (mucosal morphology) in Barrett's esophagus by using narrow band imaging. Gastrointest Endosc 2006;64: 155-66.

11. Kara MA, Peters FP, Rosmolen WD. High-resolution endoscopy plus chromoendoscopy or narrow-band imaging in Barrett's esophagus: a prospective randomized crossover study. Endoscopy 2005;37: 929-36.

12. Kiesslich R, Kanzier S, Vieth M, Moehler M, Neidig J, Thanka Nadar BJ, Schilling D, Burg J, Nafe B, Neurath MF, Galle PR. Minimal change esophagitis: Prospective comparison of endoscopic and histological markers between patients with non erosive reflux disease and normal controls using magnifying endoscopy. Dig Dis 2004; 22; 221-7.
13. Kumagai $Y$, Inoue $H$, Nagai $K$, Kawano $T$, Iwai T. Magnifying endoscopy, stereoscopic microscopy, and the microvascular architecture of superficial esophageal carcinoma. Endoscopy. 2002;34:369-75.

14. Kusnetsov K, Lambert R, Rey JF. Narrow band imaging : Potential and limitations. Endoscopy 2006;38:76-81.

15. Lee YC, Lin JT, Chiu HM, Liao WC, Chen CC, Tu CH, Tai CM, Chiang $\mathrm{TH}$, Chiu YH, Wu MS, Wang HP. Intraobserver and interobserver consistency for grading esophagitis with narrow band imaging. Gastrointest Endosc 2007; 66: 230-6.

16. Moraes-Filho JP, Navarro-Rodriguez T, Barbuti R, Eisig J, Chinzon D, Bernardo W; Brazilian Gerd Consensus Group. Guidelines for the diagnosis and management of gastroesophageal reflux disease: na evidence-based consensus. Arq Gastroenterol 2010; 47(1):99115.

17. Muto M, Horimatsu T, Ezoe Y, Hori K, Yukawa Y, Morita S, Miyamoto $\mathrm{S}$, Chiba T. Narrow band imaging of the gastrointestinal tract. J Gastroenterol 2009;44:13-25.

18. Muto M, Horimatsu T, Ezoe Y, Morita S, Miyamoto S. Improving visualization tecniques by narrow band imaging and magnification endoscopy. J Gastroenterol and Hepatol 2009;24: 1333-46.

19. Navarro-Rodriguez T, de Moraes-Filho JP, Arakaki E, Chinzon $D$, Zaterka S, Iriya K, Laudanna AA. The screening sensitivity of endoscopy, acid perfusion test and 24-hour $\mathrm{pH}$-monitoring to evaluate esophagitis in patients with heratburn and histological esophagitis. Arq Gastroenterol 1997; 34(3):148-56.

20. Rastogy A, Mathur S, Wani SB. Narrow band imaging findings correlate with histological changes in gastroesophageal reflux disease (GERD) patients [abstract]. Gastroenterol 2007;132:A277.

21. Reddymasu SC, Sharma P. Advances in endoscopy imaging of the esophagus. Gastroenterol Clin N Am 2008;37: 763-74.

22. Sano $Y$, Kobayashi M, Hamamoto Y. New diagnostic method based on color imaging using narrow- band imaging (NBI) system for gastrointestinal tract. [abstract] Gastrointest Endosc. 2001;53:AB 125.

23. Sharma P, Wani S, Bansal A, Hall S, Puli S, Mathur S, Rastogi A. A feasibility trial of narrow band imaging endoscopy in patients with gastroesophageal reflux disease. Gastroenterol 2007; 133: 454-64.

24. Sharma P, Bansal A, Mathur S. The utility of a novel narrow band imaging endoscopy system in patients with Barrett's esophagus. Gastrointest Endoscopy 2006;64: 167-75.

25. Singh R, Nordeen N, Shanmuganathan G, Thurairajah PH, Bhat YM. Current consensus for role of NBI in diagnosis of superficial neoplasia in the upper digestive tract.Role of narrow band imaging in Barrett's esophagus. Digest Endosc 2011;23(Supl.1): 83-5.

26. Spechler SJ. Barrett's esophagus. Gastrointest Endosc Clin N Am 2011; 21: 1-7

27. Tseng PH, Chen CC, Chiu HM, Liao WC, Wu MS, Lin JT, Lee YC, Wang HP. Performance of narrow band imaging and magnification endoscopy in the prediction of therapeutic response in patients with gastroesophageal reflux disease. J Clin Gastroenterol 2011; 45: 501-6.

28. Wang KK, Sampliner RE. Update guidelines 2008 for the diagnosis, surveillance and therapy of Barrett's esophagus. Am J Gastroenterol 2008;103:788-97.

29. Wolfsen HC, Crook JE, Krishna M. Prospective, controlled tandem endoscopy study of narrow bandd imaging for dysplasia detection in Barrett's esophagus. Gastroenterol 2008;135: 24-31.

30. Yoshida T, Inoue H, Usui S, Satodate H, Fukami N, Kudo SE. Narrowband imaging system with magnifying endoscopy for superficial esophageal lesions. Gastrointest Endosc. 2004;59:288-95. 